\title{
Regulation by Dietary Carbohydrates of Intermediary Metabolism in Liver and Muscle of Two Isogenic Lines of Rainbow Trout
}

\author{
Xuerong Song ${ }^{1,2,3}$, Lucie Marandel ${ }^{1}$, Sandrine Skiba-Cassy ${ }^{1}$, Geneviève Corraze ${ }^{1}$, \\ Mathilde Dupont-Nivet ${ }^{4}$, Edwige Quillet ${ }^{4}$, Inge Geurden ${ }^{1}$ and Stephane Panserat ${ }^{\text {* }}$. \\ 1 UMR1419 Nutrition, Metabolisme, Aquaculture, Aquapôle, E2S UPPA, INRA, Université de Pau et des Pays de l'Adour, \\ Saint-Pée-sur-Nivelle, France, ${ }^{2}$ University of Chinese Academy of Sciences, Beijing, China, ${ }^{3}$ State Key Laboratory \\ of Freshwater Ecology and Biotechnology, Institute of Hydrobiology, Chinese Academy of Sciences, Wuhan, China, ${ }^{4}$ GABI, \\ INRA, AgroParisTech, Université Paris-Saclay, Jouy-en-Josas, France
}

Rainbow trout (Oncorhynchus mykiss) is recognized as a typical "glucose-intolerant" fish, and the limits of dietary carbohydrate utilization have been investigated for many years. In this study, the objective was to test the molecular effects of dietary carbohydrates on intermediary metabolism in two major metabolic tissues, liver

OPEN ACCESS

Edited by:

Oscar Monroig,

Consejo Superior de Investigaciones Científicas (CSIC), Spain

Reviewed by:

Amit Kumar Sinha,

University of Arkansas at Pine Bluff,

United States

Tiziano Verri,

University of Salento, Italy

*Correspondence:

Stephane Panserat

stephane.panserat@inra.fr

Specialty section:

This article was submitted to

Aquatic Physiology,

a section of the journal

Frontiers in Physiology

Received: 10 August 2018

Accepted: 22 October 2018

Published: 13 November 2018

Citation:

Song $X$, Marandel $L$,

Skiba-Cassy S, Corraze G, Dupont-Nivet M, Quillet E, Geurden I and Panserat S (2018) Regulation by Dietary Carbohydrates of Intermediary

Metabolism in Liver and Muscle

of Two Isogenic Lines of Rainbow

Trout. Front. Physiol. 9:1579.

doi: 10.3389/fphys.2018.01579 and muscle. Another objective was also to study if the response to carbohydrate intake depended on the genetic background. We fed two isogenic lines of rainbow trout (named A22h and N38h) with high carbohydrate diet (carbohydrate, 22.9\%) or low carbohydrate diet (carbohydrate, 3.6\%) for 12 weeks. Carbohydrates were associated with higher feed utilization owned by the well-known protein-sparing effect, with better fish growth performance. However, atypical regulation of glycolysis and gluconeogenesis in liver and absence of $h k$ and glut4 induction in muscle, were also observed. Regarding the effects of carbohydrates on other metabolism, we observed an increased, at a molecular level, of hepatic cholesterol biosynthesis, fatty acid oxidation and mitochondrial energy metabolism. Genetic variability (revealed by the differences between the two isogenic lines) was observed for some metabolic genes especially for those involved in the EPA and DHA biosynthetic capacity. Finally, our study demonstrates that dietary carbohydrate not only affect glucose metabolism but also strongly impact the lipid and energy metabolism in liver and muscle of trout.

Keywords: glycolysis, gluconeogenesis, fatty acid metabolism, cholesterol metabolism, mitochondrial metabolism, genetic variability

Abbreviations: $\Delta 6$-fad, acyl-CoA 6-desaturase (delta-6 desaturase); abcal, ATP-binding cassette transporter A1; abcg5, ATP-binding cassette transporter G5; abcg8, ATP-binding cassette transporter G8; acly, adenosine triphosphate citrate lyase; atp 5a, ATP synthase, $\mathrm{H}^{+}$transporting, mitochondrial $\mathrm{F} 1$ complex, alpha subunit 1 ; cox2 and cox4, cytochrome $\mathrm{C}$ oxidase; $c p t 1 a$, carnitine $O$-palmitoyltrasferase $1 \mathrm{~A} ; c p t 1 b$, carnitine $O$-palmitoyltrasferase $1 \mathrm{~B}$; $c s$, citrate synthase; cyp7al, cholesterol 7alpha-monooxygenase; $\mathrm{dhcr}$, 7-dehydrocholesterol reductase; ef $1 \alpha$, elongation factor-1 alpha; elovl2, elongation of very long-chain fatty acid protein 2; elovl5, elongation of very long-chain fatty acid protein 5; fas, fatty acid synthase; $f b p 1 b 1, f b p 1 b 2$ and $f b p 1 a$, fructose 1,6-bisphosphatase, paralogs; $g 6 p c a, g 6 p c b 1 a, g 6 p c b 1 b, g 6 p c b 2 a$ and $g 6 p c b 2 b$, glucose 6phosphatase, paralogs; $g 6 p d h$, glucose 6-phosphate dehydrogenase; gcka and gckb, glucokinase, paralogs; glut $2 a$ and glut $2 b$, glucose transporter type 2, paralogs; glut4a and glut4b, glucose transporter type 4, paralogs; $\mathrm{H}-\mathrm{CHO}$, high carbohydrate diet; $h k$, hexokinase; $h m g c s$, hydroxymethylglutaryl-CoA synthase; hoad, 3-hydroxyacyl-CoA dehydrogenase; L-CHO, low carbohydrate diet; lxra, liver X receptor A; pck1, pck2, phosphoenolpyruvate carboxykinase, paralogs; pfkla, pfklb, 6 phosphofructokinase, liver type, paralogs; pfkmaa, pfkmab, pfkmba and pfkmbb, 6-phosphofructokinase, muscle type, paralogs; $p k l r$, pyruvate kinase, liver type; $p k m a a, p k m a b, p k m b a$ and $p k m b b$, pyruvate kinase, muscle type, paralogs; $q c r 2$, ubiquitinol cytochrome c reductase core protein 2; sdhb, succinate dehydrogenase (ubiquinone) iron-sulfur subunit; srebp-2, sterol regulatory element-binding protein 2 . 


\section{INTRODUCTION}

Fish liver is the main tissue involved in the regulation of glucose homeostasis (Pilkis and Granner, 1992; Klover and Mooney, 2004). Dietary glucose enters the liver passing through the cellular barrier by using the specific glucose transporter 2 , and then it is catabolized through glycolysis pathway for providing ATP, being stored as glycogen or being converted into lipid if in excess (Panserat et al., 2009; Polakof et al., 2011, 2012; Kamalam et al., 2012). To explain the poor use of dietary carbohydrates by rainbow trout, a poor induction of hepatic lipogenesis and an absence of inhibition of hepatic gluconeogenesis have been put forward as major reasons for post-prandial hyperglycemia (Enes et al., 2009; Polakof et al., 2012). Recently, using two specific isogenic trout lines $\mathrm{A} 32 \mathrm{~h}$ and $\mathrm{AB} 1 \mathrm{~h}$, we confirmed that the first steps of glycolysis and gluconeogenesis catalyzed by the glucokinase and the phospenolpyruvate carboxykinase were regulated as expected at the molecular level by dietary carbohydrates; by contrast, surprisingly, some of the genes encoding the last key enzymes involved in glycolysis were down-regulated whereas some of the genes encoding gluconeogenic enzymes were up-regulated (Song et al., 2018). These isogenetic fish are highly considerable for their low inter-individual variability of each genotype (Quillet et al., 2007), whether these results could be observed one more time in standard families remain questionable. Thus, to be confirmed, these unexpected observations related to glucose metabolism (Song et al., 2018) have to be renewed in other fish trout lines, presently the A22h and N38h isogenic lines. In addition, tissues other than liver may be important for glucose use in fish, such as white muscle, the largest tissue in fish. Even though some studies revealed that muscle glycogen was increased by carbohydrate intake (Soengas et al., 1996; Hemre et al., 2002), it seems that there was a low capacity of inducting glycolysis as reflected by low hexokinase activities (Kirchner et al., 2005). Because relative few studies have focused on glucose metabolism in muscle, it is done in the present study using the two isogenic trout lines A22h and N38h.

Dietary glucose is not only a source of energy (catabolism) but is also one of the main metabolic intermediaries which could also affect the synthesis (anabolism) of other biologically important compounds (Wilson, 1994; Polakof et al., 2012). Indeed, carbohydrate-enriched diets can lead to an enhancement of lipogenesis - even at a low level - (Towle et al., 1997; SkibaCassy et al., 2009), a decrease of fatty acid oxidation (Randle, 1998), an increase of the long chain polyunsaturated fatty acid (LC-PUFA) which induce synthesis of EPA and DHA (Seiliez et al., 2003; Kamalam et al., 2013). H-CHO also affect hepatic cholesterol metabolism (Kamalam et al., 2012; Deng et al., 2013; Zhu et al., 2017) and modify the energy metabolism in the mitochondria (Panserat et al., 2017). Our objective in the present study is thus to analyze, for the first time, the effect of dietary carbohydrate in these non-glucose metabolic pathways in rainbow trout.

In this context, we fed the two new isogenic trout lines named $\mathrm{A} 22 \mathrm{~h}$ and $\mathrm{N} 38 \mathrm{~h}$ with either a $\mathrm{L}-\mathrm{CHO}$ or a $\mathrm{H}-\mathrm{CHO}$ for 12 weeks (the same diets used for the A23h and AB1h in our previous study; Song et al., 2018). We analyzed growth performance, whole body composition, plasma metabolites and glycogen contents, with the analysis of the mRNA levels of the key hepatic-muscle enzymes involved in the glucose metabolism including glycolysis and gluconeogenesis, lipid metabolism including lipogenesis, fatty acid oxidation and LCPUFA biosynthesis, cholesterol metabolism and mitochondrial energy metabolism.

\section{MATERIALS AND METHODS}

\section{Ethics Statement}

Experimentation was conducted in the INRA experimental facilities (Donzacq, UMR Numéa, St-Pée-sur-Nivelle, France) authorized for animal experimentation by the French veterinary service which is the competent authority (A 64-495-1). The experiments were in strict accordance with EU legal frameworks related to the protection of animals used for scientific research (Directive 2010/63/EU) and according to the National Guidelines for Animal Care of the French Ministry of Research (decree ${ }^{\circ}{ }^{\circ} 2013-118$, February 1st, 2013). In agreement with ethical committee "Comité d'éthique Aquitain poissons oiseaux" (C2EA-73), the experiment reported here did not need approval by a specific ethical agreement since it implies only classical rearing practices with all diets used in the experimental formulated to cover all the nutritional requirements of rainbow trout (The National Research Council [NRC], 2011).

\section{Fish Experimental Diets}

Low carbohydrate diet and $\mathrm{H}-\mathrm{CHO}$ were manufactured at INRA, Donzacq, Landes, France. They were formulated as extruded pellets, the temperature of extruded pellets was $37^{\circ} \mathrm{C}$, and the pressures were 46 and 43 bars for L-CHO and $\mathrm{H}-\mathrm{CHO}$ diets respectively. The two dietscontained different carbohydrates contents but with the same level of proteins and lipids as shown in Table 1. Dietary protein $(\sim 48 \%)$ was provided by fishmeal and soluble fish protein concentrate, dietary lipid $(8 \sim 11 \%)$ was provided by fish oil and fishmeal, and gelatinized starch was included as carbohydrate source because of its higher digestibility (The National Research Council [NRC], 2011) [3.6\% (L-CHO) and 22.9\% (H-CHO) respectively]. The digestible gelatinized starch in $\mathrm{H}-\mathrm{CHO}$ diet was compensated by non-digestible cellulose in L-CHO diet (in order to maintain the same level of proteins), which implied a difference in digestible energy content between both diets.

\section{Isogenic Fish Lines, Nutritional Experiment and Sampling Procedure}

Two heterozygous isogenic lines of rainbow trout (Oncorhynchus mykiss) were obtained by mating sires and dams from homozygous isogenic lines (Peima, France). The homozygous lines used as broodstock had been previously established after 
TABLE 1 | Formulation and proximate composition of the two experimental diets.

\begin{tabular}{|c|c|c|}
\hline & L-CHO & $\mathrm{H}-\mathrm{CHO}$ \\
\hline \multicolumn{3}{|l|}{ Ingredients (\%) } \\
\hline Fish meal ${ }^{1}$ & 60.0 & 60.0 \\
\hline $\begin{array}{l}\text { Soluble fish protein } \\
\text { concentrate }^{2}\end{array}$ & 6.0 & 6.0 \\
\hline Fish oil ${ }^{3}$ & 6.0 & 6.0 \\
\hline Starch $^{4}$ & 0 & 25.0 \\
\hline Vitamin premix ${ }^{5}$ & 1.5 & 1.5 \\
\hline Mineral premix ${ }^{6}$ & 1.5 & 1.5 \\
\hline Cellulose $^{7}$ & 20.0 & 0 \\
\hline Wheat ${ }^{8}$ & 5.0 & 0 \\
\hline \multicolumn{3}{|c|}{ Proximate composition } \\
\hline Crude protein (\% DM) & 47.7 & 47.8 \\
\hline Crude lipid (\% DM) & 11.3 & 8.1 \\
\hline $\begin{array}{l}\text { Gross energy ( } \mathrm{kJ} \mathrm{g}^{-1} \\
\mathrm{DM})\end{array}$ & 20.5 & 20.8 \\
\hline Carbohydrates (\% DM) & 3.6 & 22.9 \\
\hline \multicolumn{3}{|c|}{ 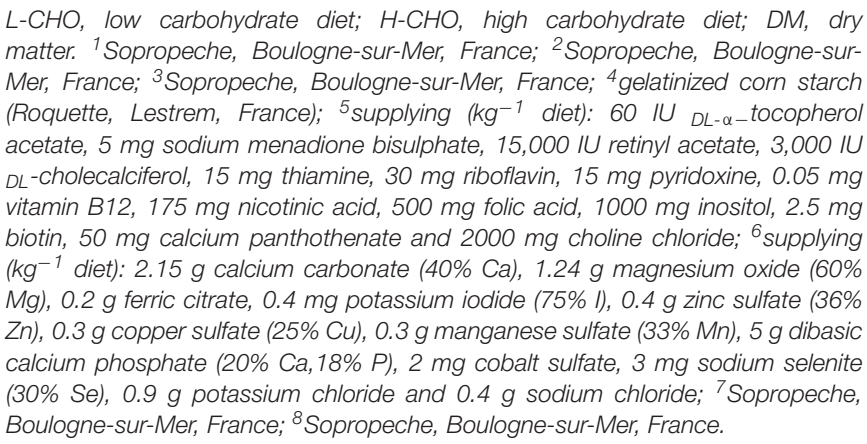 } \\
\hline
\end{tabular}

two generations of gynogenesis and then maintained by within line single pair mating using sex reversed XX males (Quillet et al., 2007). Eggs from fully homozygous females from line B57 were mixed and fertilized in two separated batches with milt from two homozygous sires from A22 and N38 lines to produce heterozygous lines named as $\mathrm{A} 22 \mathrm{~h}$ and $\mathrm{N} 38 \mathrm{~h}$ respectively. Therefore, differences between the two lines can be attributed only to genetic differences of paternal origin, whilst all individuals within one line shared the same genotype.

Rainbow trout were reared at $18^{\circ} \mathrm{C}$ in the INRA experimental facilities at Donzacq, Landes, France under natural photoperiod. During the trial, water dissolved oxygen was $9 \mathrm{mg} \mathrm{L}^{-1}$, ammonia $<0.01 \mathrm{mg} \mathrm{L}^{-1}$, nitrite $<0.04 \mathrm{mg} \mathrm{L}^{-1}$, nitrate was about $17 \mathrm{ppm}$. The quantity of flow was $0.3^{*} \mathrm{~s}^{-1}$ by tank, all water of each tank was changed 8 times each hour, and the water volume was $130 \mathrm{l}$ per tank. Fish of each line $(\sim 5 \mathrm{~g})(\mathrm{A} 22 \mathrm{~h}$ and $\mathrm{N} 38 \mathrm{~h}$ ) were randomly distributed into tanks at the density of $20 \mathrm{fish} / \mathrm{tank}$, each line being fed with (L-CHO) or without carbohydrates $(\mathrm{H}-\mathrm{CHO})$. Fish were reared in triplicates for all the experimental conditions ( 2 lines $* 2$ diets in triplicate i.e., $n=12$ tanks in total). All fish were fed twice daily with an interval $8 \mathrm{~h}$ to apparent satiation. After 12 weeks of feeding, two fish per tank were randomly sampled at $6 \mathrm{~h}$ after the last meal, known to be the peak of posprandial glycemia in rainbow trout fed with carbohydrates at $18^{\circ} \mathrm{C}$ (Polakof et al., 2012; Kamalam et al., 2017). Trout were anesthetized with benzocaine $(30 \mathrm{mg} / \mathrm{L})$ and killed by a sharp blow to the head. Blood was removed from the caudal vein via heparinized syringes and centrifuged $(3000 \mathrm{~g}, 5 \mathrm{~min}$ ). The plasma recovered was immediately frozen and kept at $-20^{\circ} \mathrm{C}$ until analysis. The fresh liver and muscle were collected and immediately frozen in liquid nitrogen and then kept at $-80^{\circ} \mathrm{C}$. Later, six more fish per tank were randomly sampled at $48 \mathrm{~h}$ after the last meal. They were immediately frozen and kept at $-20^{\circ} \mathrm{C}$ for whole body composition determination.

\section{Chemical Analysis for Diets and Whole-Body Composition}

The chemical composition of diets and fish were analyzed by the following procedures: protein content $(\mathrm{N} \times 6.25)$ was determined by Kjeldahl method after acid digestion; fat was determined by petroleum ether extraction (Soxtherm), gross energy was determined in an adiabatic bomb calorimeter (IKA, Heitersheim Gribheimer, Germany); starch content was determined by an enzymatic method (in vivo Labs).

\section{Metabolites Analysis}

Plasma glucose, triglyceride and cholesterol were determined by using commercial kits. Plasma glucose and triglyceride were assayed by the kits from Biomerieux, Marcy I'Etoile, France, and the kit for plasma cholesterol determination was from Sobioda, France. They were adapted to microplate format according to the manufacturer's instructions. Liver and muscle glycogen was determined by a hydrolysis technique previously described by Good et al. (1993) and Song et al. (2018).

\section{mRNA Levels Analysis}

Liver and muscle samples were extracted using TRIzol reagent (Invitrogen, Carlsbad, CA, United States), according to the manufacturer's recommendations and were quantified by spectrophotometry (absorbance at $260 \mathrm{~nm}$ ). The integrity of the samples was assessed using agarose gel electrophoresis. $1 \mu \mathrm{g}$ of total mRNA per sample was reverse transcribed into cDNA using the SuperScript III reverse transcriptase kit (Invitrogen, Carlsbad, CA, United States) with random primers (Promega, Charbonnieres, France) according to the manufacturer's instructions.

mRNA levels of the selected genes were determined by quantitative real-time (q) RT-PCR. efl $\alpha$ was regarded as reference gene which was stably expressed in the studies of Olsvik et al. (2005) and the primers sequences of target genes had already been published in previous studies (Marandel et al., 2015, 2016; Liu et al., 2017; Panserat et al., 2017; Zhu et al., 2017) shown in Table 2. The paralogous genes were named according to ZFIN Nomenclature guidelines ${ }^{1}$ by Marandel et al. (2015). In the present study we analyzed the mRNA levels of genes encoding glycolytic enzymes ( $g c k$, coding the glucokinase - EC: 2.7.1.2; $h k$, coding the hexokinase - EC: 2.7.1.1; pfkl and $p f k m$ coding for the 6-phosphofructokinase - EC: 2.7.1.11, pkl and pkm, coding the pyruvate kinase - EC: 2.7.1.40) and gluconeogenesis ( $p c k$

\footnotetext{
${ }^{1}$ http://zfin.org/
} 
TABLE 2 | Primer sequences and accession numbers for qPCR analysis.

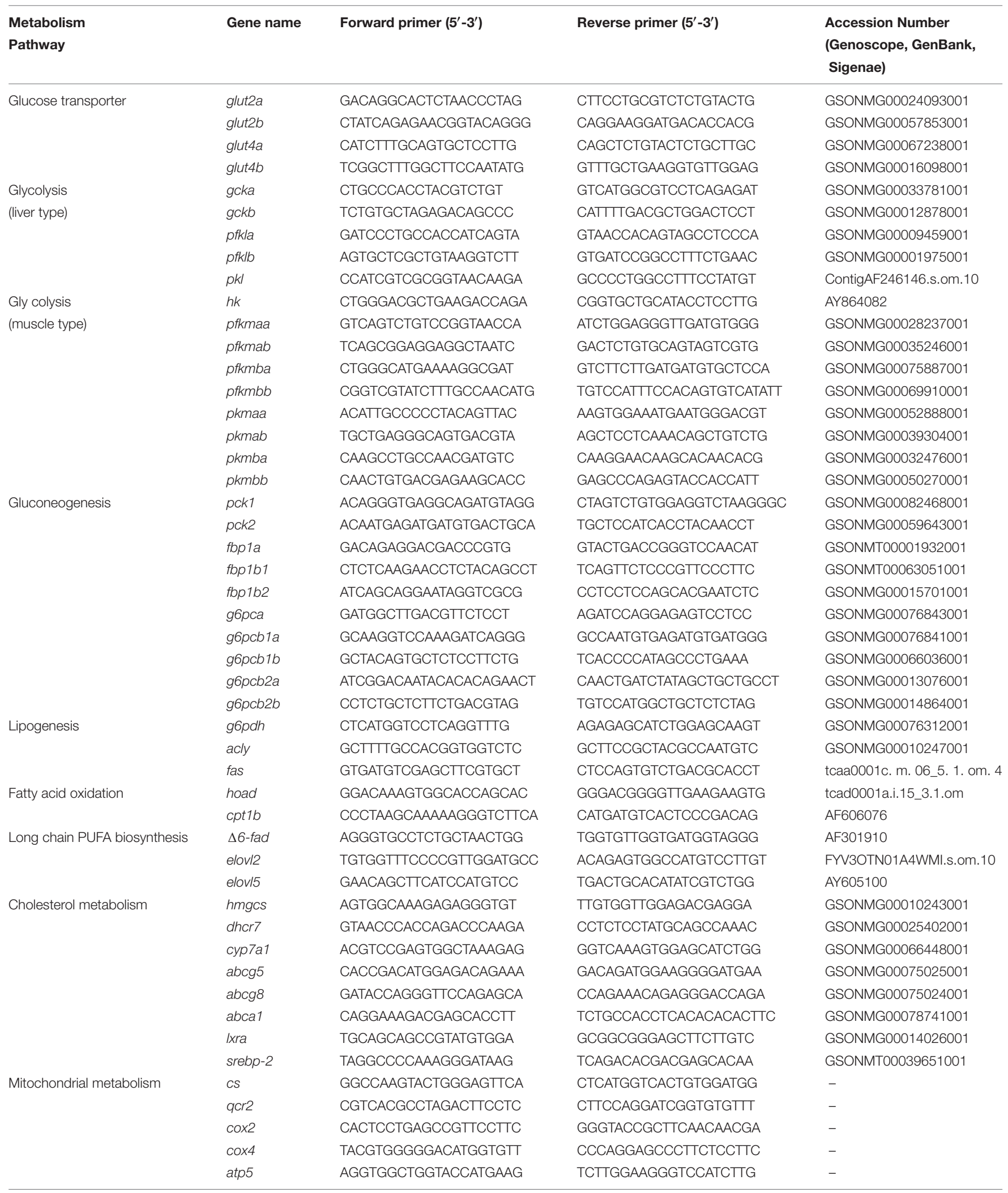


TABLE 2 | Continued

\begin{tabular}{|c|c|c|c|c|}
\hline $\begin{array}{l}\text { Metabolism } \\
\text { Pathway }\end{array}$ & Gene name & Forward primer $\left(5^{\prime}-3^{\prime}\right)$ & Reverse primer $\left(5^{\prime}-3^{\prime}\right)$ & $\begin{array}{l}\text { Accession Number } \\
\text { (Genoscope, GenBank, } \\
\text { Sigenae) }\end{array}$ \\
\hline & sdhb & CCCAGGATCAAGAAGTTCCA & TTAAGCAGGCCAGTGTGTTG & - \\
\hline Reference gene & ef1 $\alpha$ & TCCTCTTGGTCGTTTCGCTG & ACCCGAGGGACATCCTGTG & AF498320 \\
\hline
\end{tabular}

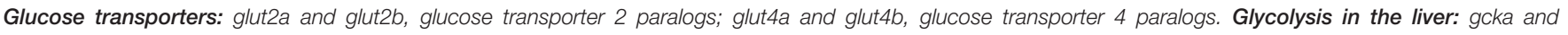

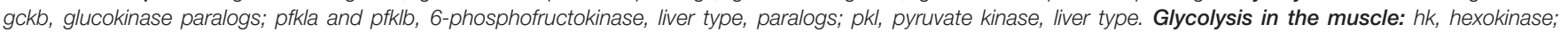

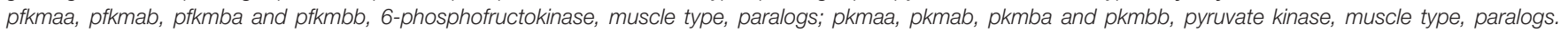

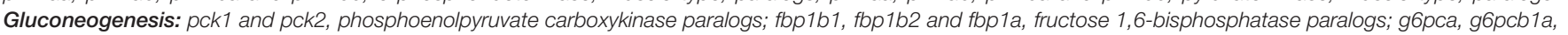

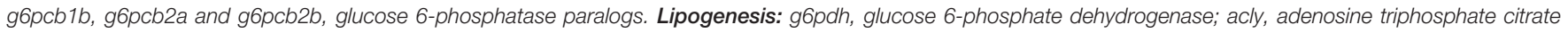

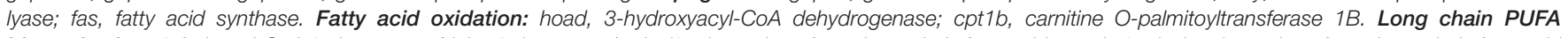

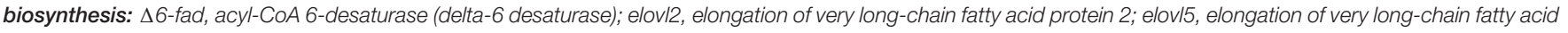

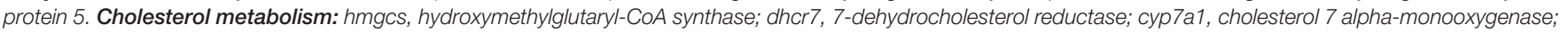

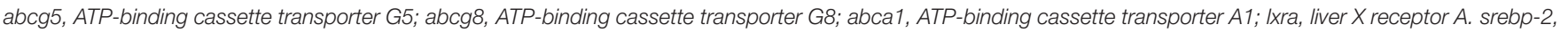

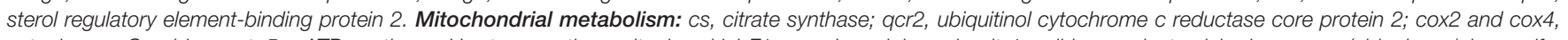

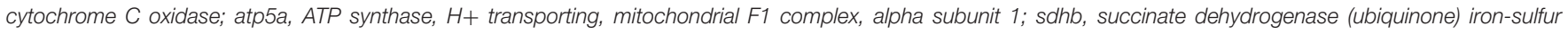
subunit. Reference gene: ef $1 \alpha$, elongation factor-1 alpha.

coding the phosphoenolpyruvate carboxykinase - EC: 4.1.1.32; $f b p$ coding the fructose 1,6-bisphosphatase - EC: $3.1 .3 .11 ; g 6 p c$ coding the glucose 6-phosphatase - EC: 3.1.3.9) and lipogenesis (g6pdh coding the glucose 6-phosphate dehydrogenase EC: 1.1.1.49; acly coding the adenosine triphosphate citrate lyase - EC: 2.3.3.8; fas coding the fatty acid synthase EC: 2.3.1.85) and fatty acid metabolism [hoad coding the 3hydroxyacyl-CoA dehydrogenase - EC: 1.1.1.35; cpt1 coding the carnitine $O$-palmitoyltransferase 1 - EC: 2.3.1.21; $\Delta 6$ fad coding the acyl-CoA 6-desaturase (delta-6 desaturase) EC:1.14.19.3; elovl2 and elovl5 coding the elongation of very long chain fatty acids protein - EC:2.3.1.199] and cholesterol metabolism ( $\mathrm{m} m \mathrm{gcs}$ coding the hydroxymethylglutaryl-CoA synthase - EC:2.3.3.10; dhcr7 coding the 7-dehydrocholesterol reductase - EC:1.3.1.21; cyp7a1 coding the cholesterol 7 alphamonooxygenase - EC:1.14.14.23) and mitochondrial energy metabolism (cs coding the citrate synthase - EC:2.3.3.1; $s d h b$ coding succinate dehydrogenase (ubiquinone) iron-sulfur subunit - EC:1.3.5.1).

Quantitative RT-PCRs were carried out on a Light Cycle 480 II (Roche Diagnostics, Neuilly-sur-Seine, France) using SYBR Green I Master (Roche Diagnostics GmbH, Mannheim, Germany). PCR were performed using $2 \mu \mathrm{l}$ of the diluted cDNA (76 times) mixed with $0.24 \mu \mathrm{l}$ of each primer $(10 \mu \mathrm{M}), 3 \mu \mathrm{l}$ of Light Cycle 480 SYBR Green I Master (Roche Diagnostics) and $0.52 \mu \mathrm{l}$ of DNase/RNase/protease-free water (5 prime, Hamburg, Germany) in a total volume of $6 \mu \mathrm{l}$. The qPCR were initiated at $95^{\circ} \mathrm{C}$ for $10 \mathrm{~min}$, then followed by 45 cycles of a three-step amplification program $\left(15 \mathrm{~s}\right.$ at $95^{\circ} \mathrm{C}, 10 \mathrm{~s}$ at $60^{\circ} \mathrm{C}$, $15 \mathrm{~s}$ at $\left.72^{\circ} \mathrm{C}\right)$. Melting curves were systematically monitored (5 s at $95^{\circ} \mathrm{C}, 1 \mathrm{~min}$ at $65^{\circ} \mathrm{C}$, temperature gradient $0.11^{\circ} \mathrm{C} / \mathrm{s}$ from 65 to $97^{\circ} \mathrm{C}$ ) at the end of the last amplification cycle to confirm the specificity of the amplification reaction. Each PCR assay included replicate samples (duplicate of reverse transcription and PCR amplification, respectively) and negative controls (reverse transcriptase and RNA free samples). Relative quantification of target genes expression was performed using the E-Method from the Light Cycler 480 software (version SW 1.5; Roche Diagnostics). PCR efficiencies were measured by the slope of a standard curve using serial dilution of cDNA (a pool of all cDNA samples), and they ranged between 1.8 and 2.0 .

\section{Statistical Analysis}

Normality of distributions was assessed by Shapiro-Wilk test. Data were analyzed by two-ways ANOVA to assess the differences between lines, diets and interactions. If interactions between diets and lines were statistically significant, a post hoc Tukey test was applied to compare all the groups. Analyses were performance with $\mathrm{R}$ software (v.3.3.3)/R Commander Package. Treatment effects and interactions were considered statistically significant at $p<0.05$. Results were presented as means $\pm \mathrm{SD}(n=6$ samples per group).

\section{RESULTS}

\section{Growth Performance and Whole-Body Composition}

After 12 weeks, growth performance of the two isogenic fish fed with or without carbohydrate were obtained. Regarding the effect of the diet, feed intake (FI), specific growth rate (SGR), feed efficiency (FE), and protein retention efficiency (PRE) were significantly higher in trout fed $\mathrm{H}-\mathrm{CHO} \operatorname{diet}$ (Table 3, $p<0.05$ ). A significant difference of FI was found between the two lines $(p<0.05)$, N38h showed higher FI than A22h $(p<0.05)$. There were no significant interactions of lines and diets for any these traits $(p>0.05)$.

Whole body compositions were shown in the Table 4 . Whole body lipid and energy content were significantly higher in trout fed $\mathrm{H}-\mathrm{CHO}$ diet than in those fed the L-CHO diet $(p<0.05)$. Only crude lipid showed difference between fish lines, A22h having a higher body lipid than N38h $(p<0.05)$. No significant difference of whole body protein content was found $(p>0.05)$.

\section{Postprandial Plasma Metabolites Levels}

Plasma glucose, triglycerides and cholesterol were measured $6 \mathrm{~h}$ after the last meal (Table 5). Higher plasma glucose 
TABLE 3 | Growth performance and feed utilization in two isogenic lines of rainbow trout fed with low carbohydrate diet and high carbohydrate diet.

\begin{tabular}{|c|c|c|c|c|c|c|c|}
\hline \multirow{2}{*}{$\begin{array}{l}\text { Line } \\
\text { Diet }\end{array}$} & \multicolumn{2}{|c|}{$\mathrm{A} 22 \mathrm{~h}$} & \multicolumn{2}{|c|}{ N38h } & \multicolumn{3}{|c|}{$P$-value } \\
\hline & L-CHO & $\mathrm{H}-\mathrm{CHO}$ & L-CHO & $\mathrm{H}-\mathrm{CHO}$ & Line (L) & Diet (D) & $L^{*} D$ \\
\hline $\mathrm{FI}(\mathrm{g} / \mathrm{d})$ & $0.397 \pm 0.03$ & $0.490 \pm 0.02$ & $0.453 \pm 0.02$ & $0.540 \pm 0.01$ & 0.001 & $3.0 e^{-5}$ & 0.8 \\
\hline SGR (\%/d) & $1.7 \pm 0.06$ & $2.2 \pm 0.04$ & $1.8 \pm 0.06$ & $2.2 \pm 0.06$ & 0.5 & $7.7 e^{-7}$ & 0.5 \\
\hline FE & $0.9 \pm 0.03$ & $1.2 \pm 0.03$ & $0.9 \pm 0.03$ & $1.1 \pm 0.02$ & 0.3 & $2.5 e^{-7}$ & 0.7 \\
\hline PRE (\%) & $30.3 \pm 1.5$ & $37.3 \pm 0.6$ & $29.3 \pm 0.6$ & $37.3 \pm 0.6$ & 0.2 & $4.9 e^{-7}$ & 0.5 \\
\hline
\end{tabular}

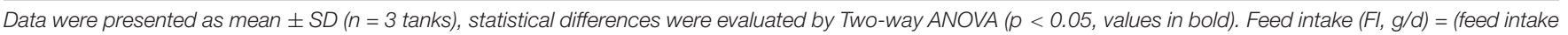

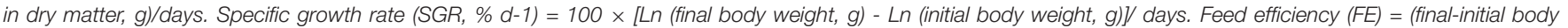
weight, g)/(feed intake in dry matter, g). Protein retention efficiency (PRE, \%) $=100 \times($ final-initial protein content, g)/(protein intake, g).

TABLE 4 | Whole body composition in two isogenic lines of rainbow trout (A22h and N38h) fed with low carbohydrate diet ( $\mathrm{L}-\mathrm{CHO})$ and high carbohydrate diet $(\mathrm{H}-\mathrm{CHO})$.

\begin{tabular}{|c|c|c|c|c|c|c|c|}
\hline \multirow{2}{*}{$\begin{array}{l}\text { Lines } \\
\text { Diets }\end{array}$} & \multicolumn{2}{|c|}{$\mathrm{A} 22 \mathrm{~h}$} & \multicolumn{2}{|c|}{ N38h } & \multicolumn{3}{|c|}{$P$-Value } \\
\hline & L-CHO & $\mathrm{H}-\mathrm{CHO}$ & L-CHO & $\mathrm{H}-\mathrm{CHO}$ & Line (L) & Diet (D) & $\mathbf{L}^{*} \mathbf{D}$ \\
\hline Crude protein (\%) & $15.6 \pm 0.3$ & $15.5 \pm 0.3$ & $15.4 \pm 0.2$ & $15.5 \pm 0.1$ & 0.6 & 0.9 & 0.4 \\
\hline Crude lipid (\%) & $7.8 \pm 0.3$ & $9.4 \pm 0.5$ & $7.3 \pm 0.2$ & $9.0 \pm 0.4$ & 0.04 & $3.4 e^{-5}$ & 0.8 \\
\hline Gross energy (kJ g ${ }^{-1}$ ) & $6.8 \pm 0.1$ & $7.5 \pm 0.2$ & $6.6 \pm 0.1$ & $7.4 \pm 0.2$ & 0.09 & $5.7 e^{-5}$ & 0.5 \\
\hline
\end{tabular}

Data were presented as mean $\pm S D(n=6$ fish), statistical differences were evaluated by Two-way ANOVA ( $p<0.05$, values in bold).

TABLE 5 | Plasma metabolites level $(\mathrm{g} / \mathrm{L})$ in two isogenic lines of rainbow trout (A22h and N38h) fed with low carbohydrate diet ( $\mathrm{L}-\mathrm{CHO})$ and high carbohydrate diet $(\mathrm{H}-\mathrm{CHO}) 6 \mathrm{~h}$ after the last meal.

\begin{tabular}{|c|c|c|c|c|c|c|c|}
\hline \multirow{2}{*}{$\begin{array}{l}\text { Lines } \\
\text { Diets }\end{array}$} & \multicolumn{2}{|c|}{$\mathrm{A} 22 \mathrm{~h}$} & \multicolumn{2}{|c|}{ N38h } & \multicolumn{3}{|c|}{$P$-value } \\
\hline & L-CHO & $\mathrm{H}-\mathrm{CHO}$ & L-CHO & $\mathrm{H}-\mathrm{CHO}$ & Line (L) & Diet (D) & $\mathbf{L}^{*} \mathbf{D}$ \\
\hline Glucose (g/L) & $0.8 \pm 0.1$ & $1.1 \pm 0.5$ & $0.9 \pm 0.05$ & $1.2 \pm 0.2$ & 0.3 & 0.01 & 0.9 \\
\hline Triglyceride (g/L) & $5.0 \pm 0.8$ & $11.8 \pm 3.5$ & $5.0 \pm 0.5$ & $10.5 \pm 2.4$ & 0.5 & $1.2 e^{-6}$ & 0.5 \\
\hline Cholesterol (g/L) & $6.6 \pm 0.7$ & $6.3 \pm 0.7$ & $5.9 \pm 0.3$ & $5.7 \pm 0.5$ & 0.007 & 0.3 & 1.0 \\
\hline
\end{tabular}

Data were presented as mean $\pm S D(n=6$ fish), statistical differences were evaluated by Two-way ANOVA ( $p<0.05$, values in bold).

and triglycerides were observed in fish fed with $\mathrm{H}-\mathrm{CHO}$ diet $(p<0.05)$ than in fish fed the L-CHO diet. Moreover, only plasma cholesterol was different bewteen trout lines, being higher in A22h $(p<0.05)$.

\section{Metabolism in Liver}

Liver glycogen contents was measured at $6 \mathrm{~h}$ after the last meal as shown in Figure 1. Liver glycogen was significantly increased in fish fed with $\mathrm{H}-\mathrm{CHO}$ diet $(p<0.05)$, whereas A22h had higher hepatic glycogen content than N38h $(p<0.05)$.

We studied mRNA levels of glucose tranporter 2 genes. The higher expression of glut $2 a$ was found in trout fed $\mathrm{H}-\mathrm{CHO}$ diet (Table 6, $p<0.05$ ) whereas glut2b was higher expressed in A22h (Table 6, $p<0.05$ ).

Regarding the glucose metabolism in liver, mRNA levels of target genes encoding key enzymes involved in glycolysis were analyzed (Table 6). Line* diet interactions were found in the mRNA levels of gcka and gckb: A22h fed H-CHO diet showed significant higher expression of gcka and gckb, then followed by $\mathrm{N} 38 \mathrm{~h}$ fed $\mathrm{H}-\mathrm{CHO}$ diet, both A22h and N38h fed L-CHO diet showed significant lower mRNA levels of gcka and $g c k b(p<0.05)$. Moreoever, higher $p f k l a$, $p f k l b$ and $p k l$ mRNA levels were observed in trout fed with L-CHO diet. We also studied the mRNA levels of key gluconeogenic enzymes (Table 6). When fed with $\mathrm{H}-\mathrm{CHO}$ diet, trout exhibited a significant decrease in the mRNA levels of $p c k 1$ and $f b p 1 b 2$ but a significant increase in the mRNA levels of $g 6 p c a$ and $g 6 p c b 1 a$ $(p<0.05)$. There were significant line* diet interactions in the mRNA levels of $f b p 1 a$ and $g 6 p c b 2 a$, an increased mRNA level of $f b p 1 a$ and $g 6 p c b 2 a$ were observed in $\mathrm{A} 22 \mathrm{~h}$ fed with $\mathrm{H}-\mathrm{CHO}$ diet $(p<0.05)$.

We further analyzed lipid metabolism in liver. We measured the mRNA levels of selected enzymes involved in fatty acid metabolism and cholesterol metabolism in the liver (Table 6). $\mathrm{H}-\mathrm{CHO}$ diet was associated with increased mRNA levels of g6pdh, acly, fas (all of them involved in lipogenesis), and also increased mRNA levels for hoad (one of the key enzyme of the $\beta$-oxidation). A22h showed significant higher mRNA levels of $\Delta 6$-fad, elovl2 and elovl5 involved in the LCPUFA biosynthesis than N38h $(p<0.05)$. Moreover, elovl5 is higher expressed in fish fed L-CHO diet $(p<0.05)$. Regarding the cholesterol metabolism, we found that hmgcs, dhcr 7 and abcg5 were expressed at higher level in fish fed carbohydrate diet, whereas mRNA levels of abcg8 and srebp2 were expressed at a higher level in A22h irrespective of the diets. 

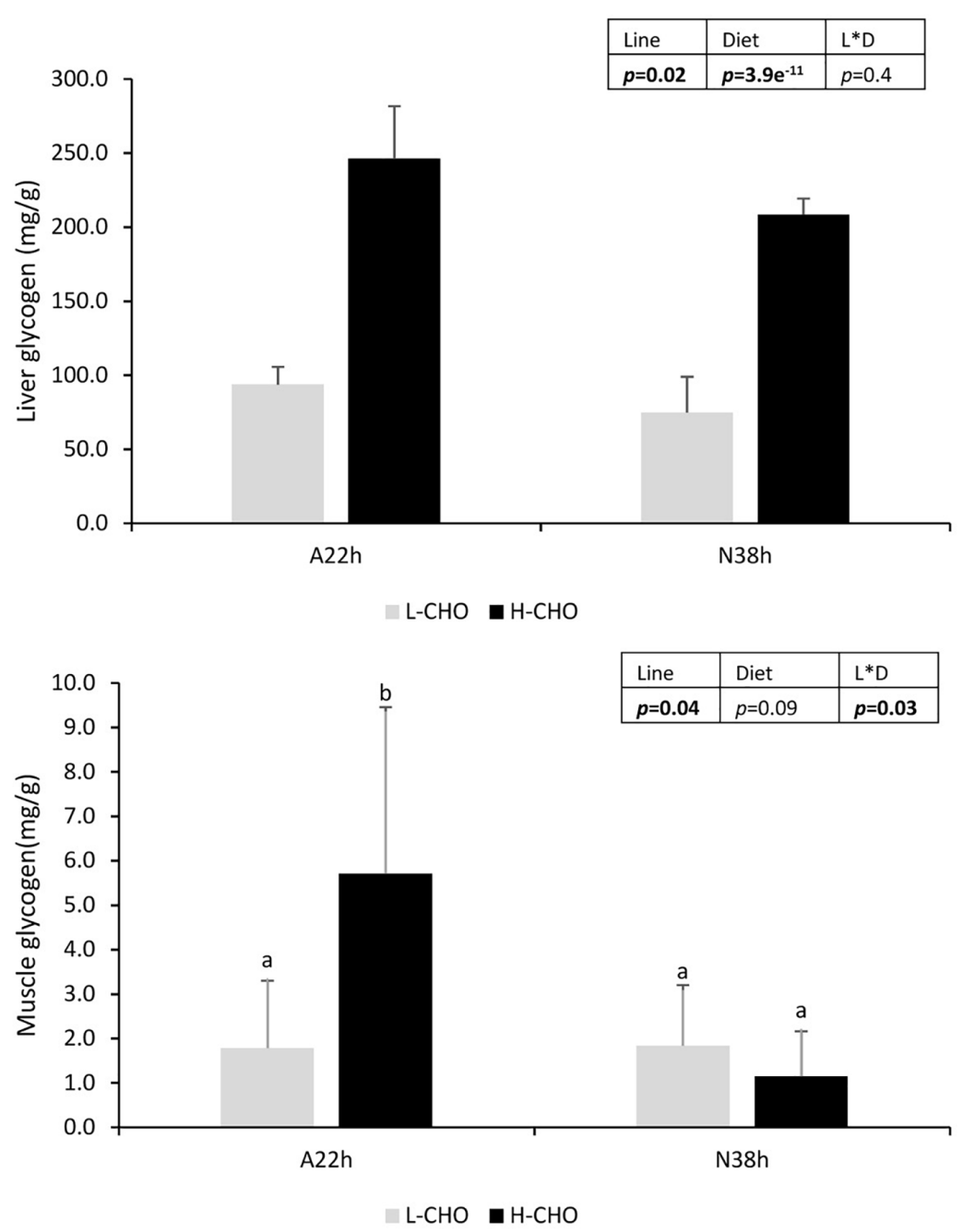

FIGURE 1 | Liver and muscle glycogen in two isogenic lines of rainbow trout (A22h and N38h) fed with low carbohydrate diet (L-CHO) and high carbohydrate diet $(\mathrm{H}-\mathrm{CHO})$. Data were presented as mean $\pm \mathrm{SD}(n=6)$, statistical differences were evaluated by Two-way ANOVA $(p<0.05$, values in bold). In case of interaction, a post hoc Tukey's test was performed $(p<0.05$, values in bold). Different superscripts indicated significant differences between treatments.

We also analyzed mitochondrial energy metabolism in trout liver as shown in Table 6. $c s, q c r 2$, cox4 and atp5a mRNA levels were higher in fish fed high carbohydrate $(p<0.05)$, but no differences were detected between the two lines $(p>0.05)$.

\section{Metabolism in Muscle}

We also studied the gene expression in the muscle (Table 7). glut4 was the main glucose tranporter form in the muscle. No difference in the expression of glut $4 a$ was found between lines and diets $(p>0.05)$. By contrast, $g l u t 4 b$ was expressed at higher level in A22h $(p<0.05)$. On the other hand, there was a strong interaction between lines and diets for the muscle glycogen, because only A22h fed with $\mathrm{H}-\mathrm{CHO}$ diet had significant higher muscle glycogen content (Figure 1, $p<0.05$ ).

Although no significant difference of $h k$ mRNA level was observed between lines nor diets $(p>0.05)$, most genes involved in the glycolysis were up-regulated by carbohydrate enriched diet.
Indeed, the mRNA levels of pfkmab, pfkmba, pfkmbb, pkmab, $p k m b a$, and $p k m b b$ were all higher in trout muscle when fish were fed with $\mathrm{H}-\mathrm{CHO}$ diet $(p<0.05)$. Moreover, some genes such as $p f k m b a, p k m a a, p k m b a$ and $p k m b b$ were higher expressed in N38h than in A22h $(p<0.05)$.

Regarding fatty acid metabolism in the muscle, we found that $c p t 1 b$ invloved in $\beta$-oxidation was higher expressed in N38h than in A22h $(p<0.05)$.

We also analyzed mitochondrial energy metabolism in the muscle of the two lines. Only a few differences were observed, cox2 and sdhb mRNA levels were lower in fish fed $\mathrm{H}-\mathrm{CHO}$ diet $(p<0.05)$.

\section{DISCUSSION}

Rainbow trout is considered as a poor user of dietary carbohydrate as reflected by the persistent postprandial 
TABLE 6 | mRNA levels of selected genes in the liver of two isogenic lines of rainbow trout (A22h and N38h) fed with low carbohydrate diet (L-CHO) and high carbohydrate diet $(\mathrm{H}-\mathrm{CHO}) 6 \mathrm{~h}$ after the last meal.

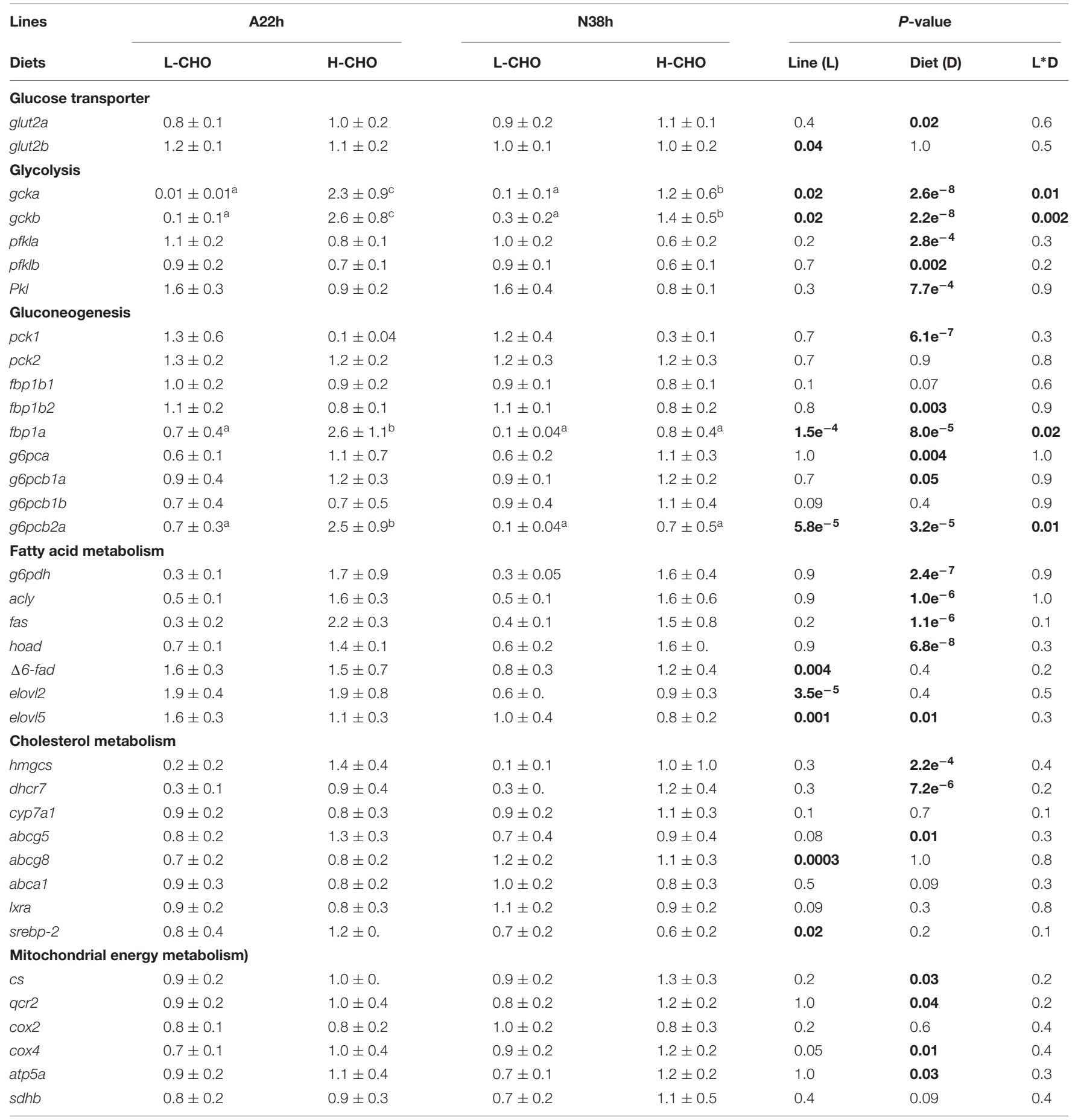

Data were presented as mean $\pm S D(n=6$ fish), statistical differences were evaluated by Two-way ANOVA $(p<0.05$, values in bold). In case of interaction, a post-hoc Tukey's test was performed ( $p<0.05$, values in bold). Different superscripts indicated significant differences between groups. glut2a and glut2b: glucose transporter 2 paralogs. gcka and gckb: glucokinase paralogs. pfkla and pfklb: 6-phosphofructokinase, liver type, paralogs. pkl: pyruvate kinase, liver type. pck1 and pck2: phosphoenolpyruvate carboxykinase paralogs. fbp1b1, fbp1b2 and fbp1a: fructose 1,6-bisphosphatase paralogs. g6pca, g6pcb1a, g6pcb1b and g6pcb2a: glucose 6-phosphatase paralogs. g6pcdh: glucose 6-phosphate dehydrogenase. acly: adenosine triphosphate citrate lyase. fas: fatty acid synthase. hoad: 3-hydroxyacyl-CoA dehydrogenase. $\triangle 6$-fad: acyl-CoA 6-desaturase (delta-6 desaturase). elovl2: elongation of very long-chain fatty acid protein 2. elovl5: elongation of very long-chain fatty acid protein 5. hmgcs: hydroxymethylg/utaryl-CoA synthase. dhcr7: 7-dehydrocholesterol reductase. cyp7a1: cholesterol 7 alpha-monooxygenase. abcg5: ATP-binding cassette transporter G5. abcg8: ATP-binding cassette transporter G8. abca1: ATP-binding cassette transporter A1. Ixra: liver X receptor A. srebp-2: sterol regulatory element-binding protein 2. cs: citrate synthase. qcr2: ubiquitinol cytochrome c reductase core protein 2. cox2 and cox4: cytochrome C oxidase. atp5a: ATP synthase, $\mathrm{H}^{+}$transporting, mitochondrial F1 complex, alpha subunit 1. sdhb: succinate dehydrogenase (ubiquinone) iron-sulfur subunit. 
TABLE 7 | mRNA levels of selected genes in the muscle of two isogenic lines of rainbow trout (A22h and N38h) fed with low carbohydrate diet (L-CHO) and high carbohydrate diet $(\mathrm{H}-\mathrm{CHO}) 6 \mathrm{~h}$ after the last meal.

\begin{tabular}{|c|c|c|c|c|c|c|c|}
\hline \multirow{2}{*}{$\begin{array}{l}\text { Lines } \\
\text { Diets }\end{array}$} & \multicolumn{2}{|c|}{ A22h } & \multicolumn{2}{|c|}{ N38h } & \multicolumn{3}{|c|}{$P$-value } \\
\hline & L-CHO & $\mathrm{H}-\mathrm{CHO}$ & L-CHO & $\mathrm{H}-\mathrm{CHO}$ & Line (L) & Diet (D) & $L^{*} \mathbf{D}$ \\
\hline \multicolumn{8}{|c|}{ Glucose transporter } \\
\hline glut4a & $1.0 \pm 0.6$ & $1.0 \pm 0.4$ & $0.8 \pm 0.1$ & $0.9 \pm 0.5$ & 0.5 & 0.8 & 0.6 \\
\hline glut4b & $1.1 \pm 0.4$ & $0.8 \pm 0.1$ & $1.1 \pm 0.2$ & $1.4 \pm 0.4$ & 0.01 & 1.0 & 0.05 \\
\hline \multicolumn{8}{|c|}{ Glycolysis } \\
\hline$h k$ & $0.9 \pm 0.4$ & $0.8 \pm 0.1$ & $0.8 \pm 0.1$ & $0.8 \pm 0.1$ & 0.4 & 1.0 & 0.4 \\
\hline pfkmaa & $1.0 \pm 0.4$ & $1.1 \pm 0.2$ & $1.0 \pm 0.3$ & $1.1 \pm 0.2$ & 0.8 & 0.6 & 0.7 \\
\hline pfkmab & $1.0 \pm 0.3$ & $1.3 \pm 0.2$ & $1.0 \pm 0.3$ & $1.4 \pm 0.3$ & 0.8 & 0.01 & 0.7 \\
\hline pfkmba & $0.4 \pm 0.2$ & $1.3 \pm 0.3$ & $0.8 \pm 0.3$ & $1.6 \pm 0.30$ & 0.003 & $4.6 e^{-7}$ & 0.8 \\
\hline$p f k m b b$ & $0.9 \pm 0.3$ & $1.2 \pm 0.3$ & $0.9 \pm 0.2$ & $1.2 \pm 0.2$ & 0.8 & 0.009 & 0.9 \\
\hline pkmaa & $0.8 \pm 0.3$ & $0.8 \pm 0.2$ & $1.1 \pm 0.5$ & $1.4 \pm 0.3$ & 0.006 & 0.3 & 0.3 \\
\hline pkmab & $1.2 \pm 0.4$ & $1.6 \pm 0.2$ & $0.9 \pm 0.2$ & $1.5 \pm 0.4$ & 0.3 & 0.02 & 0.3 \\
\hline pkmba & $0.6 \pm 0.3$ & $1.1 \pm 0.2$ & $0.9 \pm 0.2$ & $1.3 \pm 0.2$ & 0.01 & $2.3 e^{-4}$ & 1.0 \\
\hline$p k m b b$ & $0.7 \pm 0.3$ & $1.1 \pm 0.2$ & $0.9 \pm 0.2$ & $1.3 \pm 0.3$ & 0.03 & $8.4 e^{-4}$ & 0.8 \\
\hline \multicolumn{8}{|c|}{ Fatty acid oxidation } \\
\hline hoad & $1.0 \pm 0.3$ & $0.9 \pm 0.1$ & $1.0 \pm 0.2$ & $1.0 \pm 0.3$ & 0.6 & 0.9 & 0.5 \\
\hline cpt1b & $0.5 \pm 0.1$ & $0.4 \pm 0.1$ & $0.6 \pm 0.1$ & $0.8 \pm 0.1$ & 0.006 & 0.2 & 0.2 \\
\hline \multicolumn{8}{|c|}{ Mitochondrial energy metabolism } \\
\hline cs & $1.0 \pm 0.4$ & $0.8 \pm 0.1$ & $1.0 \pm 0.2$ & $1.1 \pm 0.2$ & 0.1 & 0.3 & 0.1 \\
\hline qcr2 & $0.9 \pm 0.3$ & $0.9 \pm 0.1$ & $1.0 \pm 0.1$ & $1.0 \pm 0.1$ & 0.2 & 0.9 & 0.9 \\
\hline $\operatorname{cox} 2$ & $1.1 \pm 0.4$ & $0.7 \pm 0.04$ & $1.0 \pm 0.3$ & $0.9 \pm 0.3$ & 0.9 & 0.04 & 0.1 \\
\hline $\operatorname{cox} 4$ & $0.9 \pm 0.2$ & $1.0 \pm 0.2$ & $1.0 \pm 0.1$ & $1.1 \pm 0.2$ & 0.4 & 0.1 & 0.8 \\
\hline atp5a & $1.0 \pm 0.4$ & $1.0 \pm 0.1$ & $1.0 \pm 0.2$ & $1.0 \pm 0.2$ & 1.0 & 0.9 & 0.6 \\
\hline$s d h b$ & $1.1 \pm 0.4$ & $0.7 \pm 0.1$ & $1.0 \pm 0.2$ & $0.9 \pm 0.2$ & 0.4 & 0.008 & 0.09 \\
\hline
\end{tabular}

Data were presented as mean $\pm S D$ ( $n=6$ fish), statistical differences were evaluated by Two-way ANOVA ( $p<0.05$, values in bold). glut4a and glut4b: glucose

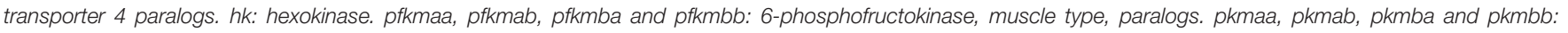

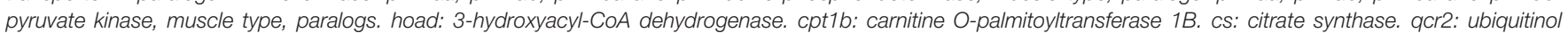

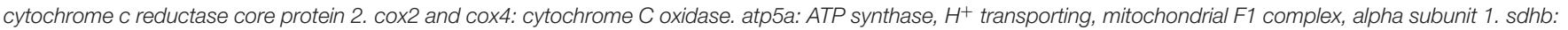
succinate dehydrogenase (ubiquinone) iron-sulfur subunit.

hyperglycemia after feeding high levels of carbohydrates or after a glucose challenge tolerance test. Although several studies explored some hypotheses to explain its poor utilization (see reviews by Polakof et al., 2012; Kamalam et al., 2017), the underlying regulations of metabolic pathways (not only glucose metabolism) are not fully understood. Some questions still need to be explored: (i) could dietary carbohydrate be a regulator of glucose metabolism and other metabolic pathways in trout? (ii) is the atypical regulation of glucose metabolism observed previously with two isogenic trout lines a general feature? Thus, we compared two new isogenic lines A22h and N38h fed with (23\%) or without $(3.6 \%)$ digestible carbohydrates to answer these two questions.

\section{Dietary Carbohydrate Is Associated With Higher Growth and Feed Efficiency (Due to Protein-Sparing Effect) and Affects Intermediary Metabolism in Liver and Muscle of Rainbow Trout Dietary Carbohydrates, Growth Performance and Glycemia}

Dietary carbohydrate is dispensable for fish (The National Research Council [NRC], 2011). By contrast, very high level of inclusion of dietary carbohydrates decreases growth performance and induced metabolic disorder in carnivorous fish (Bergot, 1979; Enes et al., 2009; Skiba-Cassy et al., 2013; Kamalam et al., 2017). In the present experiment, no negative effects of $\mathrm{H}-\mathrm{CHO}$ diet on the growth of trout, instead, an improvement of SGR was induced by $\mathrm{H}-\mathrm{CHO}$ diet. It was consistent with what had been previously reported, to some extent, appropriate supplement of dietary carbohydrate could increase fish growth performance (Singh et al., 2006; Mohanta et al., 2007). Moreover, H-CHO diet improved FE and PRE, our data suggest the better feed utilization reflecting the well-known protein-sparing effect of digestible carbohydrates as described by Kaushik et al. (1989), Kim and Kaushik (1992), and Wilson (1994).

Post-prandial glycemia is a basic indicator for assessing glucose homeostasis after feeding with carbohydrate diet (Polakof et al., 2012; Kamalam et al., 2017). In the present study, an expected increase of the plasma glucose ( $6 \mathrm{~h}$ postprandial) was found in trout fed with $\mathrm{H}-\mathrm{CHO}$ diet, but the glycemia was relatively low $(1.1-1.2 \mathrm{~g} / \mathrm{l})$ compared to that in previous studies (Wilson, 1994; Hemre et al., 2002; Panserat et al., 2009). It may be due to the low content of lipid in the diets (8-11\%), as we know that a low level of dietary lipids is associated with a better glycemia homoeostasis in trout fed with carbohydrates (Figueiredo-Silva et al., 2012). Besides, it could be due to an 
adaptative process because the experimental fish had been fed for a long period. Furthermore, we cannot also exclude that the isogenic lines represented specific genetic background associated to a particular use of nutrients.

\section{Molecular Regulation by Dietary Carbohydrates of Intermediary Metabolism in Liver}

One of the main objectives in the present study was to test the effects of feeding high vs. very low carbohydrate on hepatic intermediary metabolism, liver being the key organ for the regulation of metabolic homeostasis (Pilkis and Granner, 1992; Klover and Mooney, 2004). We observed a higher glut2a mRNA level in fish fed $\mathrm{H}$-CHO diet; this was unexpected because this gene was not reported to be affected by dietary glucose (Kirchner et al., 2008; Polakof et al., 2010; Jin et al., 2014). As we already observed such an atypical regulation by dietary carbohydrates of hepatic glycolysis and gluconeogenesis as seen before in the two other isogenetic lines (A32h and AB1h) (Song et al., 2018) suggesting that it is likely a general rule in rainbow trout whatever the genetic background (i) although gck (gcka and gckb) were markedly induced by $\mathrm{H}-\mathrm{CHO}$ diet, $p f k l a, p f k l b$ and $p k l$ genes encoding for the last two glycolytic enzymes were surprisingly lower expressed; (ii) only the two gluconeogenic genes ( $p c k 1$ and $f b p 1 b 1)$ were suppressed as expected, the other ones such as $f b p 1 a, g 6 p c a, g 6 p c b 1 a$ and $g 6 p c b 2 a$ were all higher expressed in fish fed $\mathrm{H}-\mathrm{CHO}$ diet. These data reinforced the hypothesis that an absence of concomitant increase of glycolysis and inhibition of gluconeogenesis in liver may contribute the establishment of the glucose-intolerant phenotype in rainbow trout (Enes et al., 2009; Marandel et al., 2015, 2016; Song et al., 2018).

We also analyzed some genes involved in hepatic lipid metabolism. Genes involved in lipogenesis ( $g 6 p d h$, acly and fas) were up-regulated in fish fed $\mathrm{H}$-CHO diet. Indeed, it was expected that $\mathrm{H}-\mathrm{CHO}$ diet was associated with higher capacity of fatty acid synthesis and higher levels of plasma triglycerides and lipid content in whole body as previously observed (Skiba-Cassy et al., 2009; Jin et al., 2014). The increased mRNA level of hoad involved in the lipid $\beta$-oxidation in fish fed $\mathrm{H}$ - $\mathrm{CHO}$ diet was more unexpected. As for those of lipogenesis, the genes involved in the synthesis of cholesterol ( $h m g c s$ and $d h c r 7)$ and direct elimination of hepatic cholesterol into the bile $(a b c g 5)$ were up-regulated in trout fed $\mathrm{H}-\mathrm{CHO}$ diet. This is the demonstration for the first time of an effect of dietary carbohydrate on cholesterol metabolism at a molecular level in fish. Our results confirmed previous data suggesting an effect of dietary carbohydrates on cholesterol levels in fish (trout, seabass) fed with plant-based diets (Kamalam et al., 2013; Castro et al., 2015). As no difference of plasma cholesterol was noticed between diets, our results suggested that cholesterol synthesis may have been compensated by cholesterol elimination into the bile, thus maintaining cholesterol homeostasis.

Finally, regarding mitochondrial metabolism in the liver, the mRNA levels of many of the genes involved in energy production in mitochondria ( $c s, q c r 2, c o x 4$, and atp5a) were expressed at higher level in fish fed the $\mathrm{H}-\mathrm{CHO}$ diet. These data previously observed can be linked directly to the dietary carbohydrates, but they are more probably related to the fact that the $\mathrm{H}-\mathrm{CHO}$ diet is richer in digestible energy than the L-CHO diet (cellulose is not highly digestible in trout), and thus stimulated energy metabolism in high carbohydrate treatment.

\section{Molecular Regulation by Dietary Carbohydrates of Intermediary Metabolism in Muscle}

Muscle is the largest tissue of fish and may play a major role in the efficiency of nutrients utilizations. In the present study, we analyzed the main catabolic pathways including glycolysis, $\beta$-oxidation and miochondrial energy production in the muscle. Previous experiments revolved a low capacity of glucose utilization in fish muscle because of low efficiency of glucose uptake by muscle through glucose transporter (glut4, muscle type) and poor activation of $\mathrm{HK}$ and/or PK activities when the fish were fed carbohydrate enriched diet (Hemre et al., 2002; Panserat et al., 2009). In our study, no significant differences were observed for the mRNA levels of glut4 (glut $4 a$ and glut $4 b$ ) and $h k$ in muscle confirming the previous observations (Kirchner et al., 2005; Díaz et al., 2007). However, glycolytic $p f k m$ (including paralogs $p f k m a a, p f k m a b, p f k m b a, p f k m b b$ ) and $p k m$ (including paralogs pkmaa, pkmab, pkmba, pkmbb) mRNA levels were higher in trout fed $\mathrm{H}-\mathrm{CHO}$ diet, suggesting an adaptation to dietary carbohydrates in muscle for some of the glycolytic enzymes. By contrast, and not surprisingly because the two diets were designed isolipidic, we did not find any differences in the mRNA levels of hoad and cpt $1 b$ involved in fatty acid $\beta$-oxidation. Finally, and surprisingly, some genes (cox 2 and $s d h b$ ) involved in mitochondrial energy metabolism were expressed at lower level in fish fed $\mathrm{H}-\mathrm{CHO}$ diet (with higher digestible energy) in the muscle. There were no clear reasons for these results which differ from those observed in the liver. Further studies are therefore needed to better understand this observation.

\section{Evidence for a Genetic Variability Are for Growth Performance and Intermediary Metabolism}

Another important objective of our study was to investigate if the differences may occur between the two isogenic rainbow trout (A22h and $\mathrm{N} 38 \mathrm{~h}$ ) lines when fed a diet with or without carbohydrate. In the experiment, although N38h had higher FI than A22h, no significant differences were found for growth performance and feed utilization between the two lines, thus we cannot demonstrate which genotype was advanced in carbohydrate utilization at least at the phenotype level.

Moreover, there were no significant differences in postprandial glycemia, but hepatic glycogen storage was higher in $\mathrm{A} 22 \mathrm{~h}$ than in $\mathrm{N} 38 \mathrm{~h}$ consistent with higher mRNA levels of gcka and $g c k b$ in A22h line, which could suggest a better storage of glucose through glycogen from A22h line. However, the $f b p 1 a$ and $g 6 p c b 2 a$ mRNA levels were also higher in A22h suggesting a poor control of the endogenous glucose production in this line. On the other hand, the mRNA levels of glucose transporter (glut4b) and glycolytic enzymes ( $p f k m b a$, $p k m a a, p k m b a$, and $p k m b b)$ in muscle were both lower in A22h. Therefore, there is no clear conclusion about a better regulation 
of glucose metabolism by carbohydrates by one of the two isogenic lines, as in previous comparison between two other isogenic lines (A32h and AB1h) (Song et al., 2018), suggesting the absence of polymorphism in glucose metabolism. Regarding the lipid metabolism and mitochondrial metabolism, differences between the two isogenic lines for genes involved in $\beta$-oxidation and mitochondrial metabolism used in the study were limited, except for the LC-PUFA biosynthesis capacity and cholesterol metabolism: in liver, higher mRNA levels of $\Delta 6$-fad, elovl2 and elovl5 and lower abcg8 - in charge of hepatic cholesterol transport into the bile were detected in A22h, suggesting the existence of genetic variability in the control of lipid metabolism as reflected by the clear differences in plasma cholesterol.

\section{CONCLUSION}

In conclusion, the present study described for the first time the effects of dietary carbohydrate on glucose, lipid and mitochondrial metabolism in the liver and muscle in two isogenic trout lines. These data confirmed the atypical regulation by dietary carbohydrates of hepatic glycolysis and gluconeogenesis (see Song et al., 2018 with two other studied lines) and the absence of regulation for muscle glucose transport and phosphorylation (Polakof et al., 2012). For the first time, the higher mRNA levels for genes involved in hepatic lipogenesis, cholesterol metabolism and energy metabolism as well as for those involved in glycolysis in the muscle by feeding carbohydrate were clearly demonstrated. Results also evidenced the existence of genetic variability for the expression of metabolic genes, especially for biosynthesis of EPA and DHA. Globally the present findings apport new data about the effects of dietary carbohydrates on intermediary metabolism and on the genetic control of this metabolism in rainbow trout. However, the present study on metabolic regulations was conducted only

\section{REFERENCES}

Bergot, F. (1979). Effects of dietary carbohydrates and of their mode of distribution on glycaemia in rainbow trout (Salmo gairdneri Richardson). Comp. Biochem. Phys. A 64, 543-547. doi: 10.1016/0300-9629(79)90581-4

Castro, C., Corraze, G., Panserat, S., and Oliva-Teles, A. (2015). Effects of fish oil replacement by a vegetable oil blend on digestibility, postprandial serum metabolite profile, lipid and glucose metabolism of European sea bass (Dicentrarchus labrax) juveniles. Aquacult. Nutr. 21, 592-603. doi: 10.1111/anu. 12184

Deng, J., Bi, B., Kang, B., Kong, L., Wang, Q., and Zhang, X. (2013). Improving the growth performance and cholesterol metabolism of rainbow trout (Oncorhynchus mykiss) fed soyabean meal-based diets using dietary cholesterol supplementation. Brit. J. Nutr. 110, 29-39. doi: 10.1017/S0007114512004680

Díaz, M., Capilla, E., and Planas, J. V. (2007). Physiological regulation of glucose transporter (GLUT4) protein content in brown trout (Salmo trutta) skeletal muscle. J. Exp. Biol. 210, 2346-2351. doi: 10.1242/jeb. 002857

Enes, P., Panserat, S., Kaushik, S., and Oliva-Teles, A. (2009). Nutritional regulation of hepatic glucose metabolism in fish. Fish Physiol. Biochem. 35, 519-539. doi: 10.1007/s10695-008-9259-5

Figueiredo-Silva, A. C., Panserat, S., Kaushik, S., Geurden, I., and Polakof, S. (2012). High levels of dietary fat impair glucose homeostasis in rainbow trout. J. Exp. Biol. 215, 169-178. doi: 10.1242/jeb.063933 at the molecular level, and there was no data about at enzymatic/proteic levels which could corroborate the mRNA results. Thus, more integrated researches are needed in the future.

\section{AUTHOR CONTRIBUTIONS}

SP and IG designed the study. EQ and MD-N provided the isogenic lines. GC and SS-C provided the primers of cholesterol metabolism. LM provided the primers involved in glucose metabolism. XS performed the experiments and wrote the paper. LM, SS-C, GC, MD-N, EQ, IG, and SP gave suggestions about paper writing.

\section{FUNDING}

This project has received funding from the European Union's Horizon 2020 research and innovation program under grant agreement No. 652831 (AQUAEXCEL2020). This output reflects only the author's view and the European Union cannot be held responsible for any use that may be made of the information contained therein.

\section{ACKNOWLEDGMENTS}

XS gratefully acknowledges the financial assistance provided by University of Chinese Academy of Sciences (UCAS) for the fellowship. We thank E. Plagnes-Juan, V. Véron, and A. Surget for technical assistance in the laboratory. We also acknowledge the technical staff of the INRA experimental facilities (F. Terrier, F Sandres, A Lanuque) at Donzacq, Landes, France for fish rearing and feed producing.

Good, C. A., Kramer, H., and Somogyi, M. (1993). The determination of glycogen. J. Biol. Chem. 100, 485-491.

Hemre, G., Mommsen, T. P., and Krogdahl, A (2002). Carbohydrates in fish nutrition: effects on growth, glucose metabolism and hepatic enzymes. Aquacult. Nutr. 8, 175-194. doi: 10.1046/j.1365-2095.2002. 00200.x

Jin, J., Medale, F., Kamalam, B. S., Aguirre, P., Veron, V., and Panserat, S. (2014). Comparison of glucose and lipid metabolic gene expressions between fat and lean lines of rainbow trout after a glucose load. PLoS One 9:e105548. doi: 10.1371/journal.pone.0105548

Kamalam, B. S., Medale, F., Kaushik, S., Polakof, S., Skiba-Cassy, S., and Panserat, S. (2012). Regulation of metabolism by dietary carbohydrates in two lines of rainbow trout divergently selected for muscle fat content. J. Exp. Biol. 215, 2567-2578. doi: 10.1242/jeb.070581

Kamalam, B. S., Medale, F., and Panserat, S. (2017). Utilisation of dietary carbohydrates in farmed fishes: new insights on influencing factors, biological limitations and future strategies. Aquaculture 467, 3-27. doi: 10.1016/j. aquaculture.2016.02.007

Kamalam, B. S., Meìdale, F., Larroquet, L., Corraze, G., and Panserat, S. (2013). Metabolism and fatty acid profile in fat and lean rainbow trout lines fed with vegetable oil: effect of carbohydrates. PLoS One 8:e76570. doi: 10.1371/journal. pone.0076570

Kaushik, S., Medale, F., Fauconneau, B., and Blanc, D. (1989). Effect of digestible carbohydrates on protein/energy utilization and on glucose metabolism in 
rainbow trout (Salmo gairdneri R.). Aquaculture 79, 63-74. doi: 10.1016/00448486(89)90446-8

Kim, J., and Kaushik, S. (1992). Contribution of digestible energy from carbohydrates and estimation of protein/energy requirements for growth of rainbow trout (Oncorhynchus mykiss). Aquaculture 106, 161-169. doi: 10.1016/ 0044-8486(92)90200-5

Kirchner, S., Panserat, S., Lim, P. L., Kaushik, S., and Ferraris, R. P. (2008). The role of hepatic, renal and intestinal gluconeogenic enzymes in glucose homeostasis of juvenile rainbow trout. J. Comp. Physiol. Biol. 178, 429-438. doi: 10.1007/ s00360-007-0235-7

Kirchner, S., Seixas, P., Kaushik, S., and Panserat, S. (2005). Effects of low protein intake on extra-hepatic gluconeogenic enzyme expression and peripheral glucose phosphorylation in rainbow trout (Oncorhynchus mykiss). Comp. Biochem. Phys. Biol. 140, 333-340. doi: 10.1016/j.cbpc.2004.10.019

Klover, P. J., and Mooney, R. A. (2004). Hepatocytes: critical for glucose homeostasis. Int. J. Biochem. Cell Biol. 36, 753-758. doi: 10.1016/j.biocel.2003. 10.002

Liu, J., Plagnes-Juan, E., Geurden, I., Panserat, S., and Marandel, L. (2017). Exposure to an acute hypoxic stimulus during early life affects the expression of glucose metabolism-related genes at first-feeding in trout. Sci. Rep. 7:363. doi: 10.1038/s41598-017-00458-4

Marandel, L., Dai, W., Panserat, S., and Skiba-Cassy, S. (2016). The five glucose6-phosphatase paralogous genes are differentially regulated by insulin alone or combined with high level of amino acids and/or glucose in trout hepatocytes. Mol. Biol. Rep. 43, 207-211. doi: 10.1007/s11033-016-3962-6

Marandel, L., Seiliez, I., Véron, V., Skiba-Cassy, S., and Panserat, S. (2015). New insights into the nutritional regulation of gluconeogenesis in carnivorous rainbow trout (Oncorhynchus mykiss): a gene duplication trail. Physiol. Genomics 47, 253-263. doi: 10.1152/physiolgenomics.00026.2015

Mohanta, K. N., Mohanty, S. N., and Jena, J. K. (2007). Protein-sparing effect of carbohydrate in silver barb, puntius gonionotus fry. Aqua. Nutr. 13, 311-331. doi: 10.1111/j.1365-2095.2007.00482.x

Olsvik, P., Lie, K., Jordal, A. E., Nilsen, T., and Hordvik, I. (2005). Evaluation of potential reference genes in real-time RT-PCR studies of Atlantic salmon. BMC Mol. Biol. 6:21. doi: 10.1186/1471-2199-6-21

Panserat, S., Marandel, L., Geurden, I., Veron, V., Dias, K., Plagnes-Juan, E., et al. (2017). Muscle catabolic capacities and global hepatic epigenome are modified in juvenile rainbow trout fed different vitamin levels at first feeding. Aquaculture 468, 515-523. doi: 10.1016/j.aquaculture.2016.11.021

Panserat, S., Skiba-Cassy, S., Seiliez, I., Lansard, M., Plagnes-Juan, E., Vachot, C., et al. (2009). Metformin improves postprandial glucose homeostasis in rainbow trout fed dietary carbohydrates: a link with the induction of hepatic lipogenic capacities? Am. J. Physiol. Regul. Integr. Comp. Physiol. 297, R707-R715. doi: 10.1152/ajpregu.00120.2009

Pilkis, S. J., and Granner, D. K. (1992). Molecular physiology of the regulation of hepatic gluconeogenesis and glycolysis. Annu. Rev. Physiol. 54, 885-909. doi: 10.1146/annurev.ph.54.030192.004321

Polakof, S., Alvarez, R., and Soengas, J. L. (2010). Gut glucose metabolism in rainbow trout: implication in glucose homeostasis and glucosensing capacity. Am. J. Physiol. Regul. Integr. Comp. Physiol. 299, 19-32. doi: 10.1152/ajpregu. 00005.2010

Polakof, S., Mommsen, T. P., and Soengas, J. L. (2011). Glucosensing and glucose homeostasis: from fish to mammals. J. Comp. Physiol. Biol. 160, 123-149. doi: 10.1016/j.cbpb.2011.07.006

Polakof, S., Panserat, S., Soengas, J. L., and Moon, T. W. (2012). Glucose metabolism in fish: a review. J. Comp. Physiol. Biol. 182, 1015-1045. doi: 10. 1007/s00360-012-0658-7
Quillet, E., Dorson, M., Le Guillou, S., Benmansour, A., and Boudinot, P. (2007). Wide range of susceptibility to rhabdoviruses in homozygous clones of rainbow trout. Fish Shellfish Immun. 22, 510-519. doi: 10.1016/j.fsi.2006.07.002

Randle, P. J. (1998). Regulatory interactions between lipids and carbohydrates: the glucose fatty acid cycle after 35 years. Diabetes Metab. Res. Rev. 14, 263-283. doi: 10.1002/(SICI)1099-0895(199812)14:4<263::AID-DMR233>3.0. CO;2-C

Seiliez, I., Panserat, S., Corraze, G., Kaushik, S., and Bergot, P. (2003). Cloning and nutritional regulation of a $\Delta 6$-desaturase-like enzyme in the marine teleost gilthead seabream (Sparus aurata). Comp. Biochem. Phys. Biol. 135, 449-460. doi: 10.1016/S1096-4959(03)00111-8

Singh, R. K., Balange, A. K., and Ghughuskar, M. M. (2006). Protein sparing effect of carbohydrates in the diet of Cirrhinus mrigala (hamilton, 1822) fry. Aquaculture 258, 680-684. doi: 10.1016/j.aquaculture.2006.03.049

Skiba-Cassy, S., Lansard, M., Panserat, S., and Médale, F. (2009). Rainbow trout genetically selected for greater muscle fat content display increased activation of liver TOR signaling and lipogenic gene expression. Am. J. Physiol. Regul. Integr. Comp. Physiol. 297, R1421-R1429. doi: 10.1152/ajpregu.003 12.2009

Skiba-Cassy, S., Panserat, S., Larquier, M., Dias, K., Surget, A., PlagnesJuan, E., et al. (2013). Apparent low ability of liver and muscle to adapt to variation of dietary carbohydrate: protein ratio in rainbow trout (Oncorhynchus mykiss). Br. J. Nutr. 109, 1359-1372. doi: 10.1017/S0007114512 003352

Soengas, J. L., Strong, E. F., Fuentes, J., Veira, J. A. R., and Adnrés, M. D. (1996). Food deprivation and refeeding in Atlantic salmon Salmo salar: effects on brain and liver carbohydrate and ketone bodies metabolism. Fish Physiol. Biochem. 15, 491-511. doi: 10.1007/BF01874923

Song, X., Marandel, L., Dupont-Nivet, M., Quillet, E., Geurden, I., and Panserat, S. (2018). Hepatic glucose metabolic responses to digestible dietary carbohydrates in two isogenic lines of rainbow trout. Biol. Open 7:bio032896. doi: 10.1242/bio. 032896

The National Research Council [NRC] (2011). Nutrient Requirements of Fish and Shrimp. Washington, DC: The National Academies Press. doi: 10.1146/annurev. nutr.17.1.405

Towle, H. C., Kaytor, E. N., and Shih, H. M. (1997). Regulation of the expression of lipogenic enzyme genes by carbohydrate. Annu. Rev. Nutr. 17, 405-433. doi: 10.1146/annurev.nutr.17.1.405

Wilson, R. P. (1994). Utilization of dietary carbohydrate by fish. Aquaculture 124, 67-80. doi: 10.1016/0044-8486(94)90363-8

Zhu, T., Corraze, G., Plagnes-Juan, E., Quillet, E., Dupont-Nivet, M., and Skiba-Cassy, S. (2017). Regulation of genes related to cholesterol metabolism in rainbow trout (Oncorhynchus mykiss) fed plant-based diet. Am. J. Physiol. Regul. Integr. Comp. Physiol. 314, R58-R70. doi: 10.1152/ajpregu. 00179

Conflict of Interest Statement: The authors declare that the research was conducted in the absence of any commercial or financial relationships that could be construed as a potential conflict of interest.

Copyright (C) 2018 Song, Marandel, Skiba-Cassy, Corraze, Dupont-Nivet, Quillet, Geurden and Panserat. This is an open-access article distributed under the terms of the Creative Commons Attribution License (CC BY). The use, distribution or reproduction in other forums is permitted, provided the original author(s) and the copyright owner(s) are credited and that the original publication in this journal is cited, in accordance with accepted academic practice. No use, distribution or reproduction is permitted which does not comply with these terms. 